\title{
Students' Perceptions of an Outcome Based Peer Approach to Promote Self-Directed Learning in a Dental School Course in Biomaterials
}

\author{
Shivaughn M. Marchan \\ School of Dentistry, Faculty of Medical Science, The University of the West Indies, St. Augustine, Trinidad and Tobago \\ Email: shivaughn.marchan@sta.uwi.edu,Shivaughn.marchan.tt@gmail.com
}

How to cite this paper: Marchan, S. M. (2021). Students' Perceptions of an Outcome Based Peer Approach to Promote Self-Directed Learning in a Dental School Course in Biomaterials. Creative Education, 12, 54-61.

https://doi.org/10.4236/ce.2021.121005

Received: November 5, 2020

Accepted: January 11, 2021

Published: January 14, 2021

Copyright (อ 2021 by author(s) and Scientific Research Publishing Inc. This work is licensed under the Creative Commons Attribution International License (CC BY 4.0).

http://creativecommons.org/licenses/by/4.0/

(c) (i) Open Access

\begin{abstract}
Background and Objective: The curricula of dental schools have evolved over the last two decades in an attempt to develop graduates that are critical thinkers that can solve problems related to the overall competency based management of patients. Inherent to this process is the introduction of teaching and learning strategies that assist professional students in becoming self-directed learners early in their training. At the UWI-SOD self-directed learning influenced by peer interaction is used in part as a teaching/learning strategy in the delivery of a dental biomaterials course in the second year of study. This study aims to examine student perceptions of this strategy compared to faculty driven instruction. Methods: A 25-item survey, which was previously subjected to a face validity exercise was deployed to the Year 2 cohort after all assessments for the course were completed and final course grades published. Items explored perceptions related to the process of peer assisted learning, peer interaction during group learning, preferences between didactic lectures and peer based learning, preferences on other types of active learning strategies, and preparedness for this type of learning strategy. Items were scored on a 5-point Likert scale from 1-strongly disagree to 5-strongly agree. Overall mean scores for each item were calculated using SPSS (Version 24, IBM, Chicago). Responses were grouped as follows: scores of 1-strongly disagree and 2-disagree were grouped together to show disagreement, scores of 4-agree and 5-strongly agree to show agreement. Results: There was a response rate of $92 \%$. When the process was compared to PBL, $78 \%$ of surveyed students preferred this methodology as a learning strategy and $60 \%$ preferred didactic lectures over this peer based learning strategy. Sixty-five percent of students agreed that they learnt and assimilated knowledge from their peers
\end{abstract}


during PAL. Only $29 \%$ of students preferred PAL over purely didactic lectures. Conclusion: While more than half of the surveyed students claimed they learned from their group peers during peer sessions, the vast majority of students preferred a faculty driven instruction method for the delivery of this course.

\section{Keywords}

Dental Biomaterials, Self -Directed Learning, Peer Assisted Learning, Teaching/Learning Strategies

\section{Introduction}

Dental materials science is a core course in the curriculum of dental schools (General Dental Council, 2002). Unlike other core courses in preclinical dentistry, the content covers the chemical, physical and mechanical aspects of the various materials used in the clinical and laboratory aspects of dentistry and can resemble engineering sciences. Students should normally have some prerequisite knowledge of chemistry and physics.

At the University of the West Indies School of Dentistry (SOD), and in many dental schools, the delivery of the dental biomaterials course happens simultaneously with pre-clinical laboratory based courses such as operative dentistry and fixed and removable prosthodontics (Matthews, 2000). This allows application of learned content into physical use and handling of materials (General Dental Council, 2002).

Dental school curricula have evolved over the last 20 years from didactic based lectures that are teacher driven to active learning strategies such as problem based learning (PBL), team based learning (TBL) and case based learning (CBL) that are student driven (Hendricson et al., 2006). Active learning strategies develop critical thinking and problem solving skills that can be enhanced by peer to peer or small group interaction (Eisen, 2001). With active learning strategies, students are held responsible for their own self-directed learning and significant amounts of preparation happen outside of the classroom environment (Chen, 2010).

Since dental materials science, a core course in all dental schools, is mainly taught during the preclinical years when students have not yet been exposed to clinical patient management, the opportunity for simulated clinical based scenarios as with PBL or CBL is limited. Indeed in a study of first year dental students in Melbourne, Burrow and Dodds (2002) concluded that their findings did not support the use of PBL as a teaching methodology for dental materials science. In this same study, however, a small percentage of students admitted to enjoying learning in small groups (Burrow \& Dodds, 2002). Schweitzer and Cohen (1987) described the teaching methodology of a personal system of instruction for the 
teaching of dental materials science to dental hygiene students, however, in the context of large class cohorts such a strategy may not be feasible (Schweitzer \& Cohen, 1987).

At the SOD, modified self-directed peer based learning was used in conjunction with either face to face or online didactic lectures to deliver dental materials science. This change in course delivery was made after several years of poor summative student performance, with a didactic teaching delivery only. The modified peer based learning approach used an everted design (Table 1) or outcomes based approach where learners keep focused on covering learning objectives. The students are all part of the same cohort progressing through the degree program so they equally share a non-hierarchical status. Unlike, true peer to peer learning, the students do not choose their group peers but instead are grouped by the course teacher. The approach is a hybrid; between team based learning, without the individual and team assurance testing, and informal peer assisted learning (PAL) (Parmelee et al., 2012).

The aim of this study is to examine student perceptions as it relates to the self-directed active learning influenced by peer interaction compared with didactic delivery (either face to face or online) of course material.

\section{Method}

Ethical approval was granted by the Ethics Committee of The University of the West Indies, St. Augustine (CREC-SA.0423/06/2020) prior to the start of this study. A 25-item self-reported questionnaire was sent to the students $(n=25)$ of the current second year class via Survey Monkey on the completion of the course and all associated assessments. A cover page was included with the survey to explain its purpose and to ensure respondents that the data would be collected, analyzed and reported on anonymously. The questionnaire was previously subjected to a face validity exercise during a pilot phase where educational specialists gave their opinion on the structuring and content of individual items.

Table 1. Steps in the outcomes based peer approach to teaching/learning in dental biomaterials.

1) Core concepts. Learners are exposed to the fundamentals of the course in a traditional faculty driven classroom/lecture setting for 3 - 4 sessions.

2) Advance Assignment. Learners are given an advanced assignment and furnished with learning outcomes for a particular topic. Reading materials are supplied by the course teacher. They are expected to engage with learning materials individually.

3) Group Discussion. The students convene in groups at class time and are given questions based on the learning outcomes that must be discussed in groups for not more than an hour.

4) Faculty Guided Review. All groups reconvene with the course teacher (content specialist) to discuss the same questions in a discussion format and not a lecture format. Students can ask questions of each other or the course teacher at this point to clarify any gaps in knowledge.

5) Formative Assessment. A short 10-item formative MCQ is given to the students to test for gaps in their own knowledge. 
Twenty three items explored themes related to the process of peer assisted learning, peer interaction during group learning, preferences between didactic lectures and peer based learning, preferences on other types of active learning strategies, and preparedness for this type of learning strategy. Students indicated their responses based on a 5-point Likert scale from 1 (strongly disagree) to 5 (strongly agree). Students were also given an opportunity to complete open ended questions as it related to the course design and delivery and thoughts on group dynamics as it related to learning within the course.

Overall mean scores for each item were calculated using SPSS (Version 24, IBM, Chicago). Individual responses were collated, to show general trends of agreement versus disagreement as follows: scores of 1 strongly disagree and 2 disagree were grouped together to show disagreement, scores of 4 agree and 5 strongly agree to show agreement. These collated responses were expressed as percentage values.

\section{Results}

There was a response rate of $92 \%$. Twenty respondents were female and 3 respondents male. There was an age range from 21 to 29 years with a mean age of 22.5 years. Table 2 shows the mean scores as they relate to the perceptions of the students regarding the teaching and learning strategy. Overall $91 \%$ of the surveyed students appreciated the value of dental materials science within the framework of the Year 2 DDS curriculum. When the process was compared to $\mathrm{PBL}, 78 \%$ of surveyed students preferred this methodology as a learning strategy and $60 \%$ preferred didactic lectures over this peer based learning strategy. Fifty two percent of students responded that they felt at ease asking and answering question during class discussion versus $47 \%$ during a purely didactic lesson. Sixty five percent of students agreed that they learnt and assimilated knowledge from their peers during PAL in both the smaller groups and the larger reconvened group session discussion. Only $29 \%$ of students preferred PAL over purely didactic lectures. When students were asked about understanding difficult content; $65 \%$ of students said this was easier when didactic lectures were used compared to only $34 \%$ when PAL was utilized. Forty four percent of students agreed that there was good group dynamic during PAL.

Some of the students' comments on group interactions included: "I found the group sessions counterproductive as most of the group members hadn't properly understood the content well enough to answer the questions," "This course was especially fun if your group members did the reading that was essential."

Comments on the overall workload for this course included; "This course contained way too much reading material," "Second year semester 2 is so busy and I didn't have time to look through all the information in the reading material to get the really important concepts."

There was a comment on the usefulness of having simultaneous preclinical courses help in applying the knowledge, "Having preclinical operative techniques 
Table 2. Mean scores for individual survey items.

\begin{tabular}{|c|c|}
\hline Survey Item & Mean Score \\
\hline Dental materials seems removed from the study of dentistry & 2.11 \\
\hline Appreciates the value of dental materials science within the Year 2 dental curriculum & 4.13 \\
\hline Prefers PAL compared to PBL in covering learning objectives of new material & 3.65 \\
\hline Prefers the PAL work flow compared to PBL & 4.13 \\
\hline Prefers face to face didactic lectures for dental materials delivery & 3.65 \\
\hline Prefers online synchronous online lectures & 3.43 \\
\hline Would prefer asynchronous online lectures & 3.74 \\
\hline Comfortable asking questions during didactic lectures & 3.39 \\
\hline Easily distracted during online lectures & 3.00 \\
\hline Can tolerate about one hour of didactic teaching & 4.04 \\
\hline Fundamental lectures helped with understanding material based lectures & 4.26 \\
\hline All members of group participated in meaningful discussion during PAL & 3.21 \\
\hline Good small group dynamic & 3.04 \\
\hline Good large group dynamic & 3.65 \\
\hline Large group discussion filled in knowledge gaps from PAL sessions & 3.83 \\
\hline Understood content more with PAL versus didactic & 3.08 \\
\hline Understood content more with didactic versus PAL & 3.74 \\
\hline Authentic clarification of queries happened during large class discussion & 3.82 \\
\hline Comfortable answering/ asking peers questions & 3.30 \\
\hline Learnt and assimilated questions from peers during PAL & 3.65 \\
\hline Prefers PAL over didactic lectures for dental materials delivery & 2.87 \\
\hline Secondary school prepared me for this type of learning & 2.60 \\
\hline Undergraduate degree prepared me for this type of learning & 2.70 \\
\hline
\end{tabular}

and prosthodontics certainly helped in understanding the concepts covered both in didactic lectures and group-work."

And finally there was a comment on the importance of the course teacher in the large group discussion and understanding concepts, "Even though the class might not participate fully when the course teacher was rehashing the problem, this is where I retained most of the information. The course teacher's explanations and lecture notes brings about a better understanding."

\section{Discussion}

Approximately half of the delivered course depended on the student taking responsibility for their own learning and engaging with reading materials. It is expected that students in post-secondary education should have requisite skill and acumen to direct their own learning activities with minimal guidance of course teachers (Bembenutty, 2011). Personal attributes such as emotional stability and 
autonomy can affect the development of self-directed learning in young adults, which is normally a construct of adult learning (De Bruin., 2007). However, the success of self-directed learning is dependent in part on the building of the students' own knowledge of and exposure to a topic (Wass et al., 2011). Fundamental, faculty driven; lectures at the start of this course aimed to expose students to early core concepts related to the study of materials science, concepts that students could build upon using a mode of self-discovery. The high mean scores on the item relating to the fundamental lectures demonstrated this concept of scaffolding. These new adult learners learned initially through the instruction of the course teacher in the classroom setting prior to actively engaging with content and mastering their own actions through consciousness and control. In this way the course teacher provided temporary support or scaffold for learners as they were introduced to new concepts and theories. The mean score on the items relating to the role of the course teacher, post PAL; in filling in knowledge gaps demonstrated that there was still heavy reliance on a faculty-centered approach throughout the entire learning process.

The low mean scores associated with preparedness for active learning, solely or within a group, were surprising. Particularly, within the context of the overall curriculum and these students having been exposed to PBL in the first year of training and continuing into the second year while concurrently completing this course. The work of Walker and Lofton (2003) concluded that young adult learners within a PBL curriculum had lower perceptions of their ability and the perceived importance of self-directed learning (Walker \& Lofton, 2003). This seems to hold true for this modified peer approach that was utilized at the SOD.

There was a perception even among students within the cohort that had prior undergraduate degrees that there were not prepared for this type of learning strategy. This is in contrast to the work of Slater and Cusick (2017), who completed a systematic review on preparedness of students in health profession programs for self-directed learning. They concluded that previous educational experience had a positive influence on students' perception of self-directed learning (Slater \& Cusick., 2017). Educational experience like age and year level are common temporal constructs which with passing time could improve learners' perception and acceptance of self-directed learning strategies, either individually or from peers. Published work has shown that students engaged in self-directed learning often initially have feelings of frustration and confusion early in the process with transformation that leads to confidence and skills that lead to lifelong learning (Lunyk-Child et al., 2001). In the context of the overall program the studied cohort can be considered neophytes within the professional program and self-directed active learning strategies may still develop.

What was not considered was the learning style of the students within the cohort. While courses cannot be tailor made to accommodate every learning style, certainly a mix of teaching and learning strategies can be used to optimize learning amongst students. Work by Linares seems to suggest that learners that 
were predominantly convergers were significantly more self-directed compared to other types of learners (Linares, 1999). Future study would include an exploration of the learning styles of this cohort and how it influences the development of self-directed learning with the passage of time in a rigorous professional program.

The incorporation of the small group peer work into the teaching strategy was an attempt to foster cooperative learning where individual group members attempted to work together towards the common goal of solving problems based on the learning outcomes while at the same time holding each other responsible for individual learning and developing social skills responsible for effective group work (Cooper \& Mueck., 1990). The results of this study showed mixed results, while students gave an overall mean score of 3.04 for small group dynamic only $44 \%$ generally agreed that group dynamic was good. Further, open ended comments seem to suggest that not all members participated in a meaningful discussion and expression of views to facilitate an enriched understanding of covered content.

The results of this study must be interpreted cautiously due to the use of a small cohort at a regional university and may not be applicable to other geographic locales and educational cultures. The results of this study would seem to concur with the conclusions of Yuan et al (2012) that suggest that promoting self-directed learning is a challenging process and introducing this type of learning into the curricula requires preparation of both staff and students to facilitate and benefit from this type of learning (Yuan et al., 2012).

\section{Conclusion}

While there was some success in this modified PAL approach to enhance self-directed learning with more than half of the students stating they learned from peer interaction, the vast majority of students preferred faculty driven instruction for the delivery of dental biomaterials.

\section{Funding}

This research did not receive any specific grant from funding agencies in the public, commercial, or not-for-profit sectors.

\section{Conflicts of Interest}

The author declares no conflicts of interest regarding the publication of this paper.

\section{References}

Bembenutty, H. (2011). Introduction: Self-Regulation of Learning in Postsecondary Education. New Directions for Teaching and Learning, 2011, 3-8. https://doi.org/10.1002/tl.439

Burrow, M. F., \& Dodds, A.E. (2003). Problem Based Learning in a Traditional Curricu- 
lum: The Case of Dental Materials Science. Journal of Dental Research, 82, 106.

Chen, M.C. (2010). Relationships among Self-Directed Learning, Learning Styles, Learning Strategies and Learning Achievement for Students of Technology University in Taiwan by Using Structural Equation Models. Recent Researches in Educational Technologies, 7, 67-72.

Cooper, J., \& Mueck, R. (1990). Student Involvement in Learning: Cooperative Learning and College Instruction. Journal on Excellence in College Teaching, 1, 68-76.

De Bruin, K. (2007). The Relationship between Personality Traits and Self-Directed Learning Readiness in Higher Education Students. South African Journal of Higher Education, 21, 228-240. https://doi.org/10.4314/sajhe.v21i2.25632

Eisen, M. J. (2001). Peer-Based Professional Development Viewed through the Lens of Transformative Learning. Holistic Nursing Practice, 16, 30-42. https://doi.org/10.1097/00004650-200110000-00008

General Dental Council (2002). The First Five Years: A Framework for Undergraduate Dental Education. London: General Dental Council.

Hendricson, W. D., Andrieu, S. C., Chadwick, D. G., Chmar, J. E. et al. (2006). Educational Strategies Associated with Development of Problem-Solving, Critical Thinking, and Self-Directed Learning. Journal of Dental Education, 70, 925-936. https://doi.org/10.1002/j.0022-0337.2006.70.9.tb04163.x

Linares, A. Z. (1999). Learning Styles of Students and Faculty in Selected Health Care Professions. Journal of Nursing Education, 38, 407-414.

Lunyk-Child, O. I., Crooks, D., Ellis, P. J., Ofosu, C., \& Rideout, E. (2001). Self-Directed Learning: Faculty and Student Perceptions. Journal of Nursing Education, 40, 116-123.

Matthews, R. W. (2000). The University of the West Indies School of Dentistry. West Indian Medical Journal, 49, 14-15.

Parmelee, D., Michaelsen, L. K., Cook, S., \& Hudes, P. D. (2012). Team-Based Learning: A Practical Guide: AMEE Guide No. 65. Medical Teacher, 34, e275-e287. https://doi.org/10.3109/0142159X.2012.651179

Schweitzer, K. L., \& Cohen, P. A. (1987). Teaching Dental Materials Using the Personalized System of Instruction. Journal of Dental Education, 51, 589-593. https://doi.org/10.1002/j.0022-0337.1987.51.10.tb02146.x

Slater, C. E., \& Cusick, A. (2017). Factors Related to Self-Directed Learning Readiness of Students in Health Professional Programs: A Scoping Review. Nurse Education Today, 52, 28-33. https://doi.org/10.1016/j.nedt.2017.02.011

Walker, J. T., \& Lofton, S. P. (2003). Effect of a Problem Based Learning Curriculum on Students' Perceptions of Self Directed Learning. Issues in Educational Research, 13, 71-100.

Wass, R., Harland, T., \& Mercer, A. (2011). Scaffolding Critical Thinking in the Zone of Proximal Development. Higher Education Research \& Development, 30, 317-328. https://doi.org/10.1080/07294360.2010.489237

Yuan, H. B., Williams, B. A., Fang, J. B., \& Pang, D. (2012). Chinese Baccalaureate Nursing Students' Readiness for Self-Directed Learning. Nurse Education Today, 32, 427-431. https://doi.org/10.1016/j.nedt.2011.03.005 